\title{
Report and Recommendations on Multimedia Materials for Teaching and Learning Electricity and Magnetism
}

\begin{tabular}{|c|}
\hline Debowska \\
University of Wroclaw (PL) \\
R. Girwidz \\
Ludwig-Maximilians-Universität München (DE) \\
T. Greczylo \\
University of Wroclaw (PL) \\
A. Kohnle \\
University of St. Andrews (UK) \\
B. Mason \\
University of Oklahoma (US)
\end{tabular}

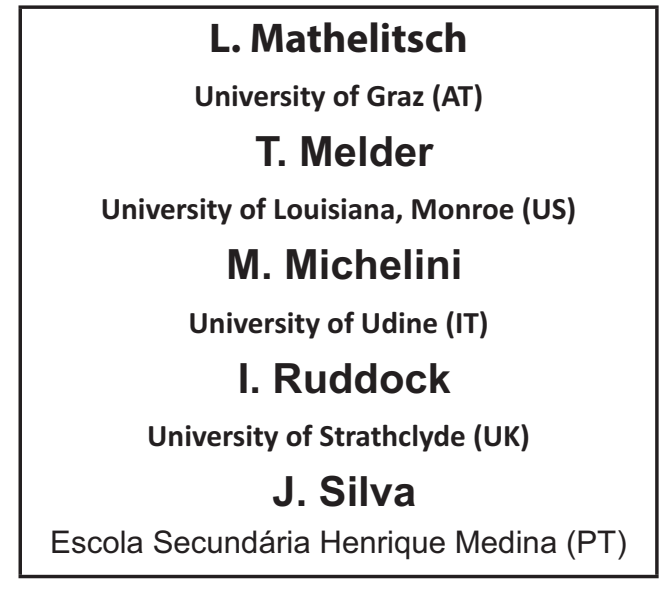

\section{Abstract}

The report presentation done by the member of the reviewing group was a part of a MPTL Symposium organized in the course of WCPE. During the symposium four talks related to the different uses of multimedia in the teaching and learning of physics were presented. The symposium was held by members of the MPTL group and covered four areas of interest: modeling and simulation, remote laboratories, video, and dissemination. We provided a review of the state of the art of each of the areas discussed, together with our vision of how the topic contributes to better teaching and learning of physics. Every year, the MPTL board carries out an evaluation of multimedia resources for teaching and learning a particular field of Physics. The paper presents the report on this year's evaluation, which covered the field of Electromagnetism and is meant to bring to the readers' attention to the described work and the recommended materials.

Keywords: MPTL, multimedia, resources, electromagnetism

\section{Introduction}

Information technology has become ubiquitous in the lifetime of our current students. Teaching and learning practices are impacted by the current wide selection of multimedia resources. Many educators and researchers are developing, and using, a variety of educational materials that make use of simulations, virtual laboratories, videos of real and animated experiments, and online tutorials based on wellestablished didactic methods [1], [2]. In physics we have many collections of high-quality resources freely available and easily accessible via the internet.

This report presents the results of a peer review of open access/open source multimedia and technologybased learning materials devoted to topics in electricity and magnetism. The peer review is part of a continuing series of annual reviews, started in 2002, carried out by an international group of physicists associated with MPTL Conference. Each year, one physics area such as Mechanic, Optics and Waves, Solid State, Nuclear and Particle Physics, Electricity and Magnetism, Statistical and Thermal Physics is chosen for review. The goals of these review processes are to identify quality media-based teaching resources and to encourage use of them. 


\section{Process}

- The evaluation process in this year's review consisted of four main steps:

- gathering a broad list of resources,

- $\quad$ sorting out quality materials suitable for reviews,

- reviewing and reporting noteworthy items,

- $\quad$ providing an overview of the review results.

The creation of a preliminary list of resources for review took advantage of a number of tools. The search started with the list created from the previous review on Electricity and Magnetism carried out in 2005 and additional items were added through web searches by students at the University of Oklahoma and comparison with the online resource databases in MERLOT ( 280 resources) and ComPADRE ( 680 resources). There was significant overlap between all of these sources, resulting in a preliminary list containing about 1,000 items. Many of these were individual resources that are part of larger collections. In the next step of the collection and review process, these individual resources are gathered into a single item for final review.

The filtering process consisted of removing items that:

- could no longer be found,

- $\quad$ were no commercial (for-fee),

- $\quad$ were copies or mirrors from other web sites were removed,

- had obvious physics errors,

- $\quad$ with little or no multimedia

resulted in about 240 resource collections that were suitable for potential review. One of us (Mason) sorted these resources into four main categories to determine which would be suitable for a full review. The resultant categories and the number in each were:

- do not review (140),

- low priority review (35) - these items had some interesting aspects but were of lower potential quality,

- $\quad$ high priority review (54) - these items were assigned to reviewers,

- $\quad$ interesting examples (9) - a few other items were kept as interesting examples mostly video collections (seen as limited potential for student engagement) and examples of materials with physics errors but ranked highly in Google searches.

The high priority review resource collections were each assigned to two or more reviewers using an online review process hosted on ComPADRE. The review rubric used here has been described in previous reports [3]. It includes three main aspects of quality multimedia learning resources: Motivation for using the resource (ease of use, attractive layout, stated purpose, and stated use), Quality of Content (relevance, scope, accuracy), and the didactic Methods and Context (flexibility, targeted audience, pedagogy, feedback, and documentation). Each area is rated on a 5-point scale, and overall ratings in each category and for the total review are given. 


\section{Resources}

The table below presents all high priority resources reviewed and those kept as interesting examples together with information about covered topic(s) and some short comments. Only 8 of them were highly ranked by one or more reviewers and they are marked with colors and presented in the table together with additional information.

\begin{tabular}{lll}
\hline URL & Topic(s) & Short comments \\
& Magnetism, & Device and experiment simulations, \\
http://amrita.vlab. & Charges, & with notes, assessments, and \\
co.in/?sub=1\&brch=192 & Resistance & references
\end{tabular}

The collection of tutorials that include theory and a simulated experiment, as well as a self-evaluation for students test their understanding, exercises for exploring the experiment, and references. One reviewer felt the combination of theory, simulation, activities, and tutorials are very noteworthy and high quality. The second reviewer felt that the simulated experiments are too structured and "cookbook" for effective learning.

http://bestphysicsvideos.blogspot.com/ search/label/Electricity\%20and\%20

E\&M

Video Channel, many sources

Magnetism

http://canu.ucalgary.ca/map/content/ circuitbuilder/basic/simulate/practice/

DC Circuits

http://canu.ucalgary.ca/map/content/ energy/work_kinetic/simulate/elfield/ applet.html
Charges, Electric

Field
Circuit Board Simulator. Demo available

Simulation of charge motion in a field

The circuit simulator is flexible so that any DC circuit can be simulated. Controls allow the change in parameters of any circuit element, although implementing changes is note always obvious. Unfortunately, the graphics and interface are somewhat dated using abstract symbols and a square virtual circuit board for the circuits design. There are no pedagogical resources except for the noteworthy demo/tutorial at http://canu.ucalgary.ca/map/content/circuitbuilder/basic/simulate/demo/

http://canu.ucalgary.ca/map/content/ fields/electric/dipole/simulate/applet.html

http://canu.ucalgary.ca/map/content/fields/ magnetic/dipole/simulate/applet.html

http://canu.ucalgary.ca/map/content/fields/ magnetic/point/simulate/applet.html

http://canu.ucalgary.ca/map/content/ force/elcrmagn/simulate/exb thomson/ applet.html

http://courseweb.stthomas.edu/ apthomas/SquishyCircuits/index.htm

http://faraday.physics.utoronto.ca/PVB/ Harrison/Flash/\#em

http://higheredbcs.wiley.com/ legacy/college/halliday/0471320005/ simulations6e/index.htm

\section{Electric Field}

Magnetism

Magnetic Field

Charges, E\&M

Fields

Circuits

Charges, Circuits

E\&M Fields, Circuits
Simulation of fields due to electric charges

Magnetic Field simulator, Current loops

Illustration of the Magnetic Field from straight wire

Charge motion in crossed electric and magnetic fields

Experiment videos, simple circuits

Flash animations and short tutorials on E\&M (All intro physics topics covered.)

Multimedia tutorials with simulations, audio, and self-tests.

(All intro physics topics.) 
http://hyperphysics.phy-astr.gsu.edu/ hbase/emcon.html

http://jacob.fe.uni-lj.si/eng/index.html

http://jakobvogel.net/legacy/index. php?url=physics/index.xml

http://lectureonline.cl.msu.edu/ mmp/ applist/applets.htm

http://matterandinteractions. org/Content/Materials/Videos/ SurfaceCharge.mov

http://micro.magnet.fsu.edu/ electromag/index.html

http://ngsir.netfirms.com/

http://ocw.mit.edu/courses/physics/802-electricity-and-magnetismspring-2002/index.htm

http://ocw.mit.edu/courses/physics/802-physics-ii-electricity-and-magnetismspring-2007/index.html

http://online.physics.uiuc.edu/courses/ phys212/gtm/simulations/index212.html

http://online.supercomet.no/

http://oyc.yale.edu/physics/phys-201

http://paer.rutgers.edu/PT3/cycleindex. php?topicid $=10$
$E \& M$

E\&M Fields, Circuits

E\&M Fields, Circuits

Charges, E\&M

Fields, Lorentz Force

Charges, current

E\&M applications, circuits

Circuits

Course: E\&M, Waves, Optics

Course: E\&M, Circuits, Waves

E\&M Fields, Currents

Conduction, Superconductivity

Course: E\&M, Circuits, Waves, Quantum

Charges, E\&M Fields, Induction
Short, hyper-linked E\&M tutorials

Virtual experiments, covers several topics on electricity and magnetism

Virtual experiments with adjustable parameters

Simple simulations of charge motion and fields. (All intro physics topics.)

Video demonstration of surface charges

Text explanations and simulations

Animations and simulations of circuit elements

MIT Open Courseware: Lecturevideos, problem sets, exams

MIT Open Courseware: Problembased and group learning

Simple illustrations of E\&M concepts

Multimedia tutorials, videos, virtual experiments, and text

Yale Open Courseware: Lecturevideos, problem sets, simulations and

Video-based activities and learning cycles

The set of resources, the use of videos for student exploration in a learning cycle is noteworthy. The explorations provide the learning goal, prior knowledge, and one or more prediction and follow-up questions. Simple experiments using common materials are used. The multimedia use is limited to videos but these are well designed for the learning goals.

http://people.clarkson.edu/ svoboda/ eta/Circuit_Design_Lab/circuit_design lab.html

http://phet.colorado.edu/en/ simulations/category/physics/ electricity-magnets-and-circuits
Circuits

Engineering design

Simulation-based explorations

Circuits, E\&M

Fields, Induction and learning environments. Research-based. 
The collection of materials provides a series of research-based interactive environments for students to explore different physics topics. Each of the simulations includes a number of lesson plans created by instructors and researchers on the PhET team. The reviewers had different opinions of the materials. All reviewers noted the open, flexible, and exploratory nature of the resources, although one reviewer felt a need for more structure. The concern was expressed that inaccurate student understandings could be reinforced by the models, although the PhET researchers study the student use of the simulations to avoid this problem. The algorithms and approximations used in the program are not given. In the E\&M materials there are four main noteworthy simulations (Circuits, Faraday, E\&M Fields, E\&M Waves) with multiple versions of some of these provided for the use of different audiences.

\begin{tabular}{|c|c|c|}
\hline $\begin{array}{l}\text { http://phys23p.sl.psu.edu/phys anim/ } \\
\text { EM/indexer EM.html }\end{array}$ & $\begin{array}{l}\text { E\&M Fields, } \\
\text { Circuits }\end{array}$ & $\begin{array}{l}\text { Animations of physical quantities } \\
\text { and concepts }\end{array}$ \\
\hline $\begin{array}{l}\text { http://physics.bu.edu/\%7eduffy/ } \\
\underline{\text { semester } 2 /}\end{array}$ & E\&M All topics & Simulation-illustrated tutorials \\
\hline $\begin{array}{l}\text { http://physics.bu.edu/ duffy/prelabs/ } \\
\text { prelabs.html }\end{array}$ & $\begin{array}{l}\text { E\&M Fields, } \\
\text { Circuits }\end{array}$ & Pre-lab worksheets with simulations \\
\hline \multicolumn{3}{|c|}{$\begin{array}{l}\text { The collection of physics explorations based on interactive simulations. The simulations are easy } \\
\text { to run using the intuitive interface. The recommended explorations will help learners focus on the } \\
\text { important physics the topics covered. The use of Easy Java Simulations provides users with the } \\
\text { capabilities of viewing and modifying the source. }\end{array}$} \\
\hline http://physics.bu.edu/ duffy/Ejs/ & $\begin{array}{l}\text { Charges, E\&M } \\
\text { Fields, Circuits }\end{array}$ & $\begin{array}{l}\text { Simulations-based student activities. } \\
\text { (All intro physics topics included.) }\end{array}$ \\
\hline $\begin{array}{l}\text { http://resources.schoolscience.co.uk/ } \\
\text { BritishEnergy/11-14/index.html }\end{array}$ & Circuits & $\begin{array}{l}\text { Tutorial with simulation-based } \\
\text { activities }\end{array}$ \\
\hline
\end{tabular}

The resource provides a focused, simple introduction to circuits suitable for primary and secondary students. The tutorial includes theory, virtual experiments, and self-tests for learners. The simulation is interactive, although it is a little hard to construct circuits at times. Many exploratory "challenge" problems are available for students to use, although one reviewer felt some problems were too scripted.

\begin{tabular}{|c|c|c|}
\hline $\begin{array}{l}\text { AccesLibre/UM/Pedago/physique/02/ } \\
\text { mnelectricite.html }\end{array}$ & Electrostatics & In French \\
\hline $\begin{array}{l}\text { http://ressources.univ-lemans.fr/ } \\
\text { AccesLibre/UM/Pedago/physique/02/ } \\
\text { mnelectro.html }\end{array}$ & Magnetostatics & In French \\
\hline $\begin{array}{l}\text { http://techtv.mit.edu/collections/ } \\
\text { physicsdemos/videos?view=list }\end{array}$ & E\&M all topics & $\begin{array}{l}\text { Video experiments with explanations } \\
\text { (Wide range of physics topics.) }\end{array}$ \\
\hline $\begin{array}{l}\text { http://vnatsci.Itu.edu/s schneider/ } \\
\text { physlets/main/index.shtml }\end{array}$ & $\begin{array}{l}\text { Electrostatics, } \\
\text { Magnetostatics, } \\
\text { Circuits }\end{array}$ & Simulation-illustrated tutorials \\
\hline$\frac{\text { http://web.mit.edu/8.02t/ }}{\text { www/802TEAL3D/index.html }}$ & E\&M Fields & $\begin{array}{l}\text { Animations and simulations of E\&M } \\
\text { Fields }\end{array}$ \\
\hline
\end{tabular}


The series of high quality simulations and illustrations of all E\&M topics. There is a particular focus on visualization of fields. In many of the illustrations there is little or no interactivity for the learner, but other simulations allow more exploration. Also of note, this is part of an Open Courseware course with all activities, labs, etc. (http://ocw.mit.edu/courses/physics/8-02-physics-ii-electricity-and-magnetismspring-2007/index.htm) providing a complete didactic context for the multimedia resources.

\begin{tabular}{|c|c|c|}
\hline $\begin{array}{l}\text { http://webphysics.davidson.edu/ } \\
\text { applets/ibe/default.html }\end{array}$ & $\begin{array}{l}\text { Charges, E\&M } \\
\text { Fields }\end{array}$ & $\begin{array}{l}\text { Interactive video experiments with } \\
\text { simulations }\end{array}$ \\
\hline $\begin{array}{l}\text { http://webphysics.davidson.edu/ } \\
\text { physletprob/ch7 in class/in class7 2/ } \\
\text { default.html }\end{array}$ & $\begin{array}{l}\text { E\&M Fields, } \\
\text { Charges, Currents }\end{array}$ & $\begin{array}{l}\text { Simulation-based illustrations of } \\
\text { E\&M physics }\end{array}$ \\
\hline $\begin{array}{l}\text { http://webphysics.davidson.edu/ } \\
\text { physletprob/ch7 in class/in class7 3/ } \\
\text { default.html }\end{array}$ & $\begin{array}{l}\text { Charges, } \\
\text { Dielectrics, Metals }\end{array}$ & $\begin{array}{l}\text { Simulation-based illustrations of } \\
\text { charges and materials }\end{array}$ \\
\hline $\begin{array}{l}\text { http://webphysics.davidson.edu/ } \\
\text { physletprob/ch9_problems/default.html }\end{array}$ & $\begin{array}{l}\text { E\&M Fields, } \\
\text { Induction }\end{array}$ & $\begin{array}{l}\text { Simulation-based exercises and } \\
\text { problems }\end{array}$ \\
\hline$\frac{\text { http://wps.aw.com/aw young }}{\text { physics } 11 / 13 / 3510 / 898593 . c w / \text { index.html }}$ & E\&M all topics & $\begin{array}{l}\text { Students tutorials and explorations } \\
\text { with simulations }\end{array}$ \\
\hline $\begin{array}{l}\text { http://www.animations.physics.unsw.edu. } \\
\text { au/electricity-magnetism/index.html }\end{array}$ & Circuits & $\begin{array}{l}\text { Multimedia-animated explanations } \\
\text { of E\&M applications and devices }\end{array}$ \\
\hline $\begin{array}{l}\text { http://www.ap.smu.ca/demos/index. } \\
\text { php?option=com content\&view=article } \\
\text { \&id=65\&ltemid }=78\end{array}$ & $\begin{array}{l}\text { Charges, } \\
\text { Induction, E\&M } \\
\text { Fields }\end{array}$ & $\begin{array}{l}\text { Video demonstrations with theory } \\
\text { and equipment }\end{array}$ \\
\hline $\begin{array}{l}\text { http://www.article19.com/shockwave/ } \\
\text { oz.htm }\end{array}$ & Circuits & $\begin{array}{l}\text { Animated simulator for simple } \\
\text { circuits }\end{array}$ \\
\hline 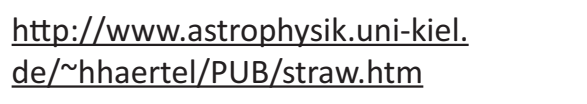 & Charge, Current & Video experiment \\
\hline$\frac{\frac{\text { http://www.batesville.k12.in.us/ }}{\text { physics/PHYNET/e\&m/efields \& }}}{\text { potential/efgApplet/EFieldGame.html }}$ & $\begin{array}{l}\text { Charges, } \\
\text { Electrostatics }\end{array}$ & $\begin{array}{l}\text { Simulation-based game to find } \\
\text { charge distributions }\end{array}$ \\
\hline$\frac{\text { http://www.cco.caltech.edu/ phys1/ }}{\text { java.html }}$ & $\begin{array}{l}\text { Circuits, E\&M } \\
\text { Fields, Charges }\end{array}$ & Illustrations of E\&M Concepts \\
\hline $\begin{array}{l}\text { http://www.compadre.org/osp/search/ } \\
\text { search.cfm?gs=224\&b=1\&qc=Modeling }\end{array}$ & E\&M all topics & $\begin{array}{l}\text { Simulation and curricular material } \\
\text { packages, open source }\end{array}$ \\
\hline
\end{tabular}

The collection of different resources from different authors all using the Easy Java Simulations platform. The type and quality of the content varies, but most are quite good. Theory and student activities are embedded with many, but not all, of the EJS models. One noteworthy aspect of the EJS environment is that all models can be opened and modified as needed. This also makes clear the algorithms and approximations being made.

\begin{tabular}{lll}
\hline http://www.concord.org/activities/ & $\begin{array}{l}\text { Electrostatics, } \\
\text { Current }\end{array}$ & $\begin{array}{l}\text { Multimedia-based tutorials with } \\
\text { student assessment and feedback }\end{array}$ \\
$\underline{\text { http://www.falstad.com/mathphysics. }}$ & E\&M Fields & $\begin{array}{l}\text { Simulations with a wide range of } \\
\text { examples }\end{array}$
\end{tabular}


http://www.ibiblio.org/links/ devmodules/electricpotential/index.html

http://www.ipes.ethz.ch/ ipes/2002Feldlinien/felder.html

http://www.jhu.edu/ virtlab/logic/ log cir.htm

http://www.magnet.fsu.edu/education/ tutorials/java/index.html

http://www.mindset.co.za/learn/s28/ $\underline{\mathrm{t} 15535}$

http://www.monterevinstitute.org/ courses/Introductory $\% 20$ Physics $\% 20$ II/nroc\%20prototype\%20files/ coursestartc.html

http://www.ndt-ed.org/ EducationResources/HighSchool/ highschool.htm

http://www.nhn.ou.edu/walkup/ demonstrations/WebAssignments/ index.html

http://www.phy.ntnu.edu.tw/ntnujava/ index.php?board $=16.0$

http://www.physics.uoguelph.ca/ applets/Intro physics/kisalev/index.html

http://www.physicsclassroom.com/ Class/circuits/

http://www.physicsclassroom.com/ Class/estatics/

http://www.sc.ehu.es/sbweb/fisica/ elecmagnet/elecmagnet.htm

http://www.surendranath.org/Apps. $\underline{\text { html }}$

http://www.teachersdomain.org/asset/ npe11 int charges/

http://www.udel.edu/ghw/ circuit-simulator/

http://www.virlab.virginia.edu/VL/ contents.htm

http://www.virtual-oscilloscope.com/

http://www.walter-fendt.de/ph14e/ index.html
Electrostatics

E\&M Fields, Inductance

Digital Circuits

E\&M Fields, Induction, Charges

E\&M Fields, Currents

E\&M all topics

Circuits, Magnetism

Charges, E\&M

Fields

E\&M Fields, Charges, Induction

Circuits

Currents, Circuits

Charges, Fields

E\&M all topics

E\&M Fields, Charges

Charges

DC Circuits

Circuits, E\&M

Fields

Oscilloscope

Magnetic Fields, Circuits, Induction
Illustrated introduction to electric potentials of charges

Interactive module on fields and induction

Tutorial and digital logic circuit builder

Short tutorials with simulations and animated illustrations

Video lessons and supplemental materials

Multimedia textbook and student learning resources, problems, self-assessments. (All intro physics topics.)

Tutorial Material with animated illustrations

Animation-based exercises and questions

Simulations with instructions and a discussion board

Interactive simulation of Kirchhoff's Rules

Hyper-linked tutorial

Hyper-linked tutorial

Online textbook with simulations, Spanish

Simple simulations of fields and charges

Tutorial with virtual experiments and exploration

Simple circuit simulator with resistors and wires

Video-based explanations of E\&M, with a focus on nanoscience

Virtual oscilloscope lab simulation

Simulations of circuits and virtual experiments 


\section{Conclusions and further plans}

The review process found items of significant value for educational purposes. Moreover the review rubrics and the reviewers' expectations together set a high bar for recognition as high-quality multimedia resources. The discrepancies between reviews were mostly the result of the different didactic expectations of the reviewers. This aspects might be of a potential topic for the investigation. These differences were usually based in different views of the proper balance between student-controlled explorations and more teacher-scaffolded learning exercises.

Few new examples of simulation-based multimedia learning resources for physics were discovered in this review. The reason might arise from flaws in the search process or too-restrictive views on quality, interactive multimedia. It might also be that the materials available from the existing developers are meeting instructors' needs. This might be a mature field with little motivation for new developers to create more materials.

Currently, a great deal of work is going into the creation of videos and online course material based around videos. Few such video collections were included in this review because most are simply filmed lectures or demos. They are online examples of face-to-face pedagogies with limited effectiveness. Videos such as these have their uses but require a great deal of context.

A search was made for mobile applications (tablet and phone-based) but the review process found very few good examples for E\&M. Most were simply vocabulary lessons and other lower-level learning activities.

\section{References}

[1] T Greczyło, E Dębowska, Finding viscosity of liquids from Brownian motion at students' laboratory, 2005 Eur. J. Phys. 26827

[2] A Wagner, S Altherr, B Eckert and H Jörg Jodl, Multimedia in physics education: teaching videos about aero and fluid dynamics, 2007 Eur. J. Phys. 28 L33

[3] M Benedict, T Bradfield ,E Debowska, T Colbert, B Eckert, B Mason, S Feiner-Valkier, T Melder, H Jodl, J Rauber, L Mathelitsch, S Sen, I Ruddock, E Sassi, R Sporken, Report and Recommendations on Available Multimedia Material for Electricity and Magnetism, Proc. of 11th European Workshop on Multimedia in Physics Teaching and Learning (MPTL XI), Szeged 2006 (http://www.mptl.eu/reports_files/ Rep_Recom_ElectMag_2006.pdf) 